\title{
Vibrio cholerae
}

National Cancer Institute

\section{Source}

National Cancer Institute. Vibrio cholerae. NCI Thesaurus. Code C86841.

A species of facultatively anaerobic, Gram negative, curved rod shaped bacteria assigned to the phylum Proteobacteria. This species is motile, oxidase and lipase positive, can use a wide variety of sugars as carbon sources, does not require salt for growth, and produces cholera toxin. V. cholerae is the causative agent of cholera. 